\title{
Storey-Based Stability of Unbraced Structural Steel Frames subjected to Variable Fire Loading
}

\author{
Lei $\mathrm{Xu}^{1}$, Terence $\mathrm{Ma}^{1}$, Yi Zhaung ${ }^{2}$ \\ ${ }^{1}$ Department of Civil and Environmental Engineering, University of Waterloo, 200 University \\ Avenue West, Waterloo, ON., N2L 3G1, Canada \\ ${ }^{2}$ RBS Architectural Engineering Design Associates, 507-140 West Dongfeng Road, Guangzhou, \\ China
}

\section{Corresponding Author:}

Lei $\mathrm{Xu}$, University of Waterloo

200 University Avenue West

Waterloo, ON. N2L 3G1

Tel: (519) 888-4567 x36882

Email: 1xu@uwaterloo.ca

\begin{abstract}
Structural steel has poor fire resistance properties and often requires thermal protection. Passive thermal protection systems such as insulation for steel members by application of spray-applied fire-resistance materials (SFRM) on surfaces of structural steel members are expensive and represent a significant portion of building costs for steel structures. Also, design codes around the world are progressing towards performance-based approaches rather than prescriptive-based approaches in design for fire safety. However, it is difficult to account realistically for all probable fire scenarios, and the actual fire resistance of a structure may vary significantly depending on the nature of the fire, location of origin and characteristics of the building. A means to define and identify the maximum and minimum fire loading scenarios causing instability of a given structure is therefore desirable. Presented in this paper is a novel global optimization approach for determining the highest temperature, lowest temperature, most localized, and most distributed fire scenarios causing instability for an unbraced structural steel frame. The investigation assumes that the columns are fire protected but the beams are unprotected, and may be extended to apply in other configurations and framing materials.
\end{abstract}


Keywords: stability, steel, frame, fire, optimization, scenario

\section{INTRODUCTION}

Structural steel frames must be thermally protected from fire loadings, due to the inherent ability for steel to conduct heat and degrade quickly under high temperatures. However, the cost of insulation represents a significant portion of building costs and it may be worth considering the removal of fire protection where it is deemed excessive. In particular, the Cardington tests [1] demonstrated that steel frames perform better when considered as a whole structure than that predicted from the testing of individual components. Since then, researchers have been developing methods for evaluating the stability of a steel frame under fire conditions $[2,3,4,5]$. This paper proposes a novel model for investigating the stability conditions of single-storey steel frames with fire-protected columns and unprotected beams when subjected to variable fire loading. It is unique in that the methodology for evaluation is in the form of an optimization problem that determines the extreme fire scenarios causing instability for a single-storey structural steel frame. The formulation of the optimization problem is based on that of the stability of unbraced steel frames subjected to non-proportional/variable loading in ambient temperature originally devised by $\mathrm{Xu}[6]$, and is an extension to account for the effects of elevated temperature proposed by Zhuang [7]. The variables in the optimization problem are the temperatures assigned to each of the beams in the bays of the model. The formulation is used to identify the highest and lowest temperature scenarios causing instability of the frame, as well as the most localized or distributed fire scenarios causing instability. Additionally, a method for determining the damage contribution of the columns is presented, which indicates the most vulnerable regions of the model when the frame is subjected to fire. Finally, two numerical examples are provided to demonstrate the efficiency of the proposed approach.

https://doi.org/10.1016/j.jcsr.2018.04.003

(C) 2018. This manuscript version is made available under the CC-BY-NC-ND 4.0 license http://creativecommons.org/licenses/by-nc-nd/4.0/ 
A brief review of the theory on storey-based frame stability and structural design for fire safety is presented in Sections 2 and 3, respectively. The proposed formulation is presented in Section 4, and the numerical examples are demonstrated in Section 5.

\section{STOREY-BASED FRAME STABILITY}

The overall stability of steel frames subjected to proportional loading was first addressed by Yura [8], who noted that in determining the stability of unbraced frames the stiffness contribution and interaction of all members in the frame must be considered, and that storey buckling must occur with all of the columns buckling simultaneously. This idea was extended by LeMessurier [9] and Lui [10], who each proposed new methodologies for evaluating the storey stability of frames.

$\mathrm{Xu}[6]$ proposed a global optimization formulation for determining the minimum and maximum variable loading scenarios that would result in buckling of unbraced frames. The overall lateral frame stiffness of the frame is evaluated based on the applied load at each column which is the variable of the optimization problem. The formulation abandons the traditional approach of assuming proportional loading, but instead determines the minimum and maximum loading cases that result in storey-based instability of a frame. The basis behind the formulation is that if the overall lateral stiffness of the frame is less than or equal to zero, then the frame is laterally unstable. The overall lateral stiffness of the frame, $S_{T}$, is the sum of the stiffness of the individual columns, $S_{c, i}$, defined by the following relation:

$$
S_{T}=\sum_{i=1}^{n} S_{c, i}=\sum_{i=1}^{n} \frac{12 E_{c, i} I_{c, i}}{L_{c, i}^{3}} \beta_{c, i}\left(\phi_{c, i}, r_{l, c, i}, r_{u, c, i}\right)
$$

where $E_{c, i}$ is the modulus of elasticity of an individual steel column, $I_{c, i}$ is the moment of inertia of the column, $L_{c, i}$ is the length of the column, and $\beta_{c, i}\left(\phi_{c, i}, r_{l, c, i}, r_{u, c, i}\right)$ is a stiffness modification https://doi.org/10.1016/j.jcsr.2018.04.003 (C) 2018. This manuscript version is made available under the CC-BY-NC-ND 4.0 license http://creativecommons.org/licenses/by-nc-nd/4.0/ 
factor of the column which accounts for stiffness degradation associated with column axial load and is defined in Equation (2) [6]. Note that the subscript $c$ corresponds to properties of the columns, and $n$ is the number of columns.

$$
\begin{gathered}
\beta_{c, i}\left(\phi_{c, i}, r_{l, c, i}, r_{u, c, i}\right)=\frac{\phi_{c, i}{ }^{3}}{12} \frac{a_{1} \phi_{c, i} \cos \phi_{c, i}+a_{2} \sin \phi_{c, i}}{18 r_{l, c, i} r_{u, c, i}-a_{3} \cos \phi_{c, i}+\left(a_{1}-a_{2}\right) \phi_{c, i} \sin \phi_{c, i}} \\
a_{1}=3\left[r_{l, c, i}\left(1-r_{u, c, i}\right)+r_{u, c, i}\left(1-r_{l, c, i}\right)\right] \\
a_{2}=9 r_{l, c, i} r_{u, c, i}-\left(1-r_{l, c, i}\right)\left(1-r_{u, c, i}\right) \phi_{c, i}{ }^{2} \\
a_{3}=18 r_{l, c, i} r_{u, c, i}+a_{1} \phi_{c, i}{ }^{2}
\end{gathered}
$$

where $\phi_{c, i}$ is the load parameter equal to $\pi \sqrt{P_{i} / P_{e i}}$ in which $P_{i}$ is the applied axial load, $P_{e i}$ is the Euler buckling load, and $r_{l, c, i}$ and $r_{u, c, i}$ are the lower and upper end rotational fixity factors of the column connections, respectively. The end fixity factors vary from 0 (pinned) to 1 (fixed) depending on the end conditions of the column, and are functions of the rotational stiffness, $R_{u, c, i}$ or $R_{l, c, i}$, at the corresponding end connections [6]:

$$
r_{u, c, i}=\frac{1}{1+3 E_{c, i} I_{c, i} / R_{u, c, i} L_{c, i}} ; \quad r_{l, c, i}=\frac{1}{1+3 E_{c, i} I_{c, i} / R_{l, c, i} L_{c, i}}
$$

By constraining the overall lateral stiffness of the frame to zero and varying the magnitudes of the loads at the columns, different combinations of loads resulting in lateral instability of the frame can be identified. The formulation can then identify the maximum and minimum total frame loads causing instability by using the following objective function, $Z[6]$ :

$$
{ }_{\min }^{\max } Z=\sum_{i=1}^{n} P_{i}
$$

The objective function is subject to the following zero lateral stiffness and individual column buckling constraints, respectively:

$$
S_{T}=\sum_{i=1}^{n} S_{c, i}=\sum_{i=1}^{n} \frac{12 E_{c, i} I_{c, i}}{L_{c, i}^{3}} \beta_{c, i}\left(\phi_{c, i}, r_{l, c, i}, r_{u, c, i}\right)=0
$$




$$
P_{1 i} \leq P_{i} \leq P_{u i}=\frac{\pi^{2} E_{c, i} I_{c, i}}{\left(K_{c, i} L_{c, i}\right)^{2}} ; \quad(i=1,2, \ldots, n)
$$

Where $P_{l i}$ and $P_{u i}$ are the lower and upper limits of the axial load $P_{i}$ on column $i$, and $n$ is the number of columns in the frame. The lower bound, $P_{l i}$, can be taken as either zero or the compressive axial load associated with the service dead load. The upper bound, $P_{u i}$ is required to prevent non-sway buckling of individual weak columns. The effective length factor $K_{c, i}$ is related to the end fixity factors of the column derived in [11], as follows:

$$
K_{c, i}=\sqrt{\frac{\left(\pi^{2}+\left(6-\pi^{2}\right) r_{u, c, i}\right) \times\left(\pi^{2}+\left(6-\pi^{2}\right) r_{l, c, i}\right)}{\left(\pi^{2}+\left(12-\pi^{2}\right) r_{u, c, i}\right) \times\left(\pi^{2}+\left(12-\pi^{2}\right) r_{l, c, i}\right)}}
$$

The minimum solution of the formulation stated in Equations. (4) can be defined as the "worstcase scenario" since it represents the least amount of loading required in order for the frame to become unstable. In contrast, the maximum loading case can be defined as a "best-case scenario" since it represents the highest possible load capacity of the frame.

\section{STRUCTURAL DESIGN FOR FIRE SAFETY}

The fire resistance of a structure is a broad term that can be defined as the duration of a fire, temperature of a member, or loading capacity that, if exceeded, results in failure of the structure, where failure can be defined in various ways [12]. Fire resistance can be evaluated using standard testing such as the ASTM E119 [13], ISO-834 [14], and Eurocode [15], or by analytical methods involving calculations. Standard fire curves are used in the tests because "the number of possible fire scenarios is usually too large and the analysis of each one is not practicable" [16]. For this reason, the testing methods for evaluating fire resistance do not always provide reliable estimates of the actual fire resistance of a structure during fire events. Also, standard testing is 
performed on individual structural elements without considering their interactions with the entire structural system as a whole. Furthermore, standard fire testing is expensive and time consuming. As such, reliable and simple analytical methods are preferred over the testing methods for determining the fire resistance of structures.

Analytical models for evaluating fire performance of steel structures have been developed over the past few decades. Of particular relevance is the definition of a relationship between the temperature of steel and its load carrying capacity. The evaluation of stability for steel members subjected to elevated temperatures involves reducing the elastic modulus using a degradation factor, such as the one presented in [17] and expressed in the following equation.

$$
E_{T}=\lambda_{T} E_{20}, \quad \lambda_{T}= \begin{cases}1.0+\frac{T}{2000 \ln (T / 1100)}, & 0^{\circ} \mathrm{C}<T \leq 600^{\circ} \mathrm{C} \\ \frac{690-0.69 T}{T-53.5}, & 600^{\circ} \mathrm{C}<T \leq 1000^{\circ} \mathrm{C}\end{cases}
$$

where $E_{T}$ is the modulus of elasticity at elevated temperature $T, \lambda_{T}$ is a material degradation factor accounting for the reduced properties at elevated temperature, and $E_{20}$ is the modulus of elasticity at ambient temperature. A plot of the material degradation factor versus temperature by this relation is shown in Figure 1. 


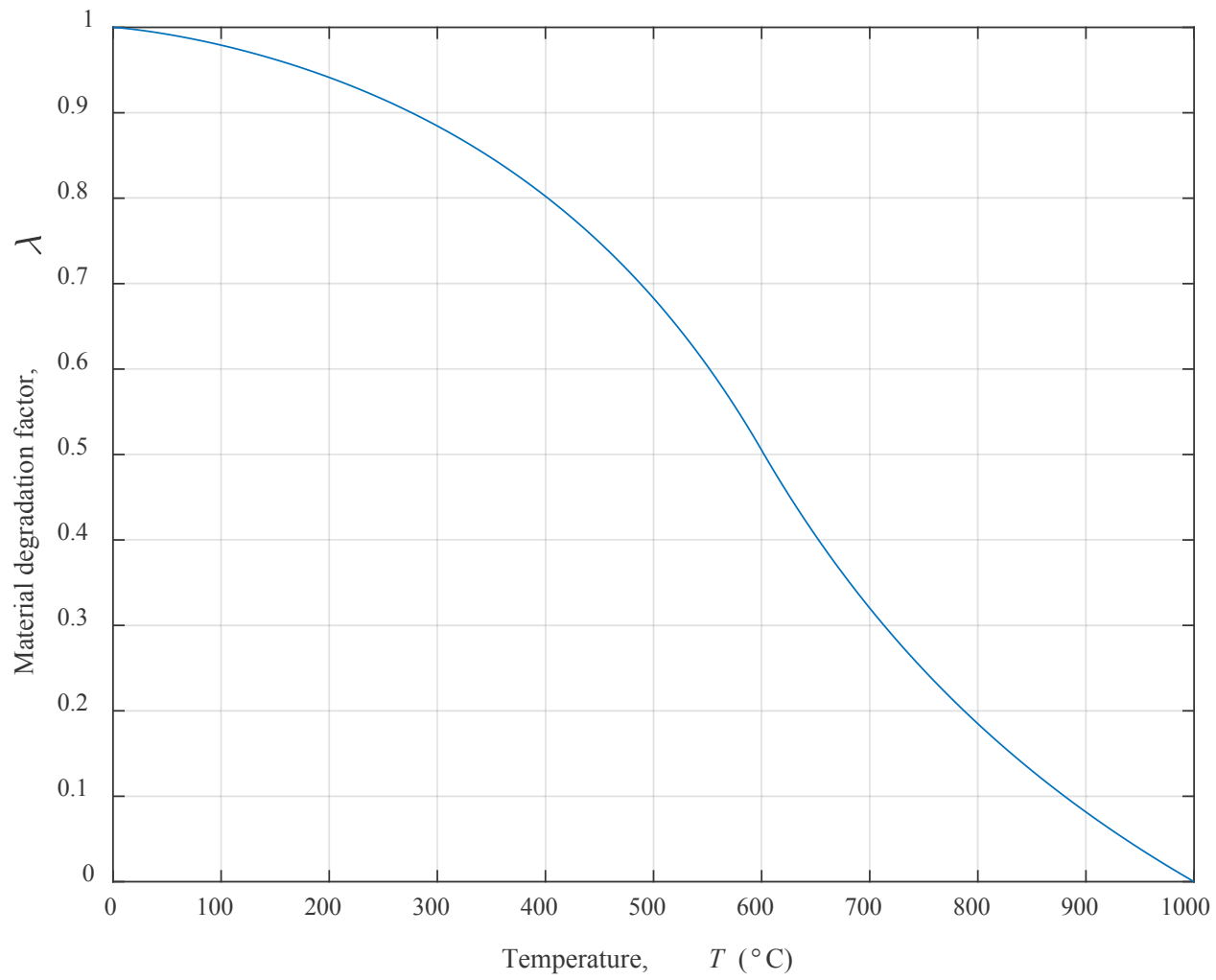

Figure 1. Degradation of elastic modulus in steel as a function of temperature

In combining the relations for reduced properties of steel with the storey-based stability optimization program results, the formulation stated in Equations. (4) can be extended to account for variable fire loading.

\subsection{Thermal Insulation}

Due to their high thermal conductivity and degrading strength properties at elevated temperatures, the use of steel structural members most often requires for the steel to be protected with thermal insulation such as SFRM, which introduces additional costs to steel construction. The British Research Establishment [1] conducted a series of fire tests on a full-scale eight-storey steel frame in its laboratory in Cardington, UK. The tests varied the amount of fire protection applied on the beams and columns in the model, and assessed the damage to the structure under various fire https://doi.org/10.1016/j.jcsr.2018.04.003

(C) 2018. This manuscript version is made available under the CC-BY-NC-ND 4.0 license http://creativecommons.org/licenses/by-nc-nd/4.0/ 
scenarios. Based on the results, Wang and Kodur [18] concluded that while fire protection is essential for the columns in order to limit widespread damage to the structure due to buckling, the protection of beams attached to composite floor systems may not be necessary, due to the redistribution of loads to the slab, and subsequently, other structural members, despite the beams losing their load-carrying capacity. Thus, the necessity of fire protection for steel beams was held in question, but no further research was conducted in this area after the September 11, 2001 collapses of the World Trade Center (WTC) towers 1, 2 and 7 were found to be caused by severe fire damage to the structures $[19,20]$. Nevertheless, it is still worth investigating the effects of removing thermal insulation in the performance-based evaluation of structures.

\section{PROPOSED FORMULATION}

As mentioned previously, structural fire safety involves evaluating fire resistance based on either standard testing or analytical methods. The proposed formulation is a performance-based, analytical method that involves evaluating the lateral stability of a structural frame subjected to elevated compartment temperatures. Similar to the original storey-based optimization formulation stated in Equations. (4), the proposed formulation abandons the traditional assumption of proportional loading and instead identifies the maximum and minimum temperature scenarios, as well as the most localized or distributed fire scenarios, that would result in storey-based instability of the frame. This is accomplished by minimizing and maximizing an appropriate objective function that is subjected to a storey-based lateral instability constraint, individual column non-sway buckling constraints, temperature constraints, and an optional single-fire constraint. 
The proposed formulation applies for any single-storey steel frame with $n$ bays and member properties shown in Figure 2.

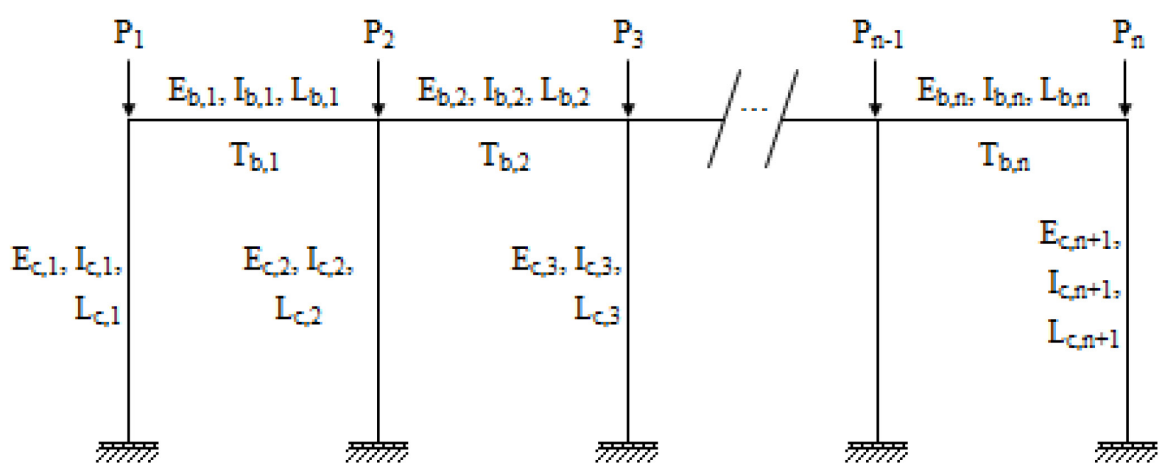

Figure 2 - General single-storey steel frame

For clarity, the properties of the columns are denoted with a subscript, $c$, and index, $i$, while properties of the beams are denoted with a subscript, $b$, and index, $j$, as necessary to distinguish between the material properties of the columns and the material properties of the beams. Each beam in the frame is assigned a temperature, $T_{b, j}$, between $20^{\circ} \mathrm{C}$ and $1000^{\circ} \mathrm{C}$, where $1000^{\circ} \mathrm{C}$ corresponds to the complete strength and stiffness degradation of the beam. Note that the temperatures of the corresponding compartments would be higher in reality due to thermal lagging effects. The aim of the proposed formulation is to assess the different combinations of $T_{b, j}$ that would result in storey-based instability of the frame, and highlight the most significant combinations based on the maximizing or minimizing of a selected objective function.

\subsection{Assumptions}

The following assumptions and limitations are required in order to use the proposed formulation:

1. The temperatures throughout each member are assumed to be uniform. To be conservative, if a member is protected in such a way that causes thermal gradients, the 
uniform temperatures obtained from this formulation should be assumed to be the maximum temperature in the temperature gradient.

2. The beams are thermally unprotected, while the columns remain fully protected. Since the temperatures of the beams in such a case will rise much faster than those of the columns, the temperatures of the beams will be varied in the analysis while the columns are set to ambient temperature (i.e. $T_{c, i}=20^{\circ} \mathrm{C}$ ). In reality, despite the application of insulation on the columns, heat transfer still occurs to increase the temperatures of the columns gradually. Also, in some cases the fire protection applied to the columns may become damaged in reality and reduce the ability of the columns to resist heating.

3. The upper limit of $P_{u i}$ in Equation (4c) represents that the failure mode of the individual column is rotational buckling.

4. The duration of fire is not considered due to the complexity and unpredictability associated with estimating time relationships for the spread of fires across multiple compartments. As such, the temperatures in the compartments are independent of each other. However, an optional constraint to limit the analysis to a single localized fire is provided and may be used to represent more realistic fire spread.

5. Out-of-plane effects are ignored, i.e. the frames are two-dimensional frames. However, the formulation may be extended in the future for the case of three-dimensional frames.

\subsection{Lateral Stiffness Constraint}

The instability of the frame is set as a constraint so that all of the combinations of $T_{b, j}$ that are considered represent fire loading conditions at the point of failure. Instability of the frame occurs when the overall lateral stiffness of the frame degrades to zero due to the effect of applied loads 
and elevated temperatures in the beams of the frame. That is, the sum of individual column lateral stiffness, $S_{c, i}$, is zero. This constraint is given in Equation 7, and is similar to the one presented in Equation (4b):

$$
\sum_{i=1}^{n} S_{c, i}=12 \sum_{i=1}^{n}\left(\frac{E_{c, i} I_{c, i}}{L_{c, i}^{3}} \beta_{c, i}\left(\phi_{c, i}, r_{l, c, i}, r_{u, c, i}\right)\right)=0
$$

The values of $E_{c, i}, I_{c, i}$ and $L_{c, i}$ remain unchanged from the ambient analysis, and the equation for $\beta_{c, i}$ is the same as in Equation (2), except that the end-fixity factors of each column, $r_{u, c, i}$ and $r_{l, c, i}$ vary based on the evaluated temperatures of the beams connected to the column, and are expressed as follows:

$$
\begin{gathered}
r_{u, c, i}=\frac{1}{1+3 E_{c, i} I_{c, i} / R_{u, c, i} L_{c, i}} ; \quad R_{u, c, i}=\sum_{j_{u}=1}^{m_{u}} R_{i, j_{u}} \\
r_{l, c, i}=\frac{1}{1+3 E_{c, i} I_{c, i} / R_{l, c, i} L_{c, i}} ; \quad R_{l, c, i}=\sum_{j_{l}=1}^{m_{l}} R_{i, j_{l}}
\end{gathered}
$$

where $m_{u}$ and $m_{l}$ are the number of beams connected to the column at the upper and lower ends, respectively. $R_{u, i, j}$ and $R_{l, i, j}$ are the rotational stiffness of the connections between the upper and lower ends of column $i$ and the $j_{u}^{\text {th }}$ or $j_{l}^{\text {th }}$ beam that is connected to the corresponding end of column $i$, expressed as [6]:

$$
R_{i, j}=\frac{6 E_{b, j} I_{b, j} r_{b, j, N}}{L_{b, j}}\left[\frac{2+v r_{b, j, F}}{4-r_{b, j, N} r_{b, j, F}}\right]
$$

where $r_{b, j, N}$ and $r_{b, j, F}$ are the near- and far-side end-fixity factors of the $j^{\text {th }}$ beam that is connected to column $i$, respectively. $\lambda_{T, j}$ is the material degradation factor for the $j^{\text {th }}$ beam due to elevated temperature defined in Equation (6), and $v$ is the ratio of rotation of the near end of the beam, $\theta_{N}$, to the rotation of the far end of the beam, $\theta_{F}$. Xu [6] demonstrated that accurate estimations of 
results can be obtained by assuming the case of asymmetric buckling, $v=1$, for unbraced partially restrained frames.

\subsection{Individual Column Buckling Constraint}

In addition to the lateral stiffness constraint presented above, the following constraint should be satisfied in order to ensure that non-sway buckling of individual column does not occur [6]:

$$
P_{l i} \leq P_{i} \leq P_{u i}=\frac{\pi^{2} E_{c, i} I_{c, i}}{\left(K_{c, i} L_{c, i}\right)^{2}} \quad(i=1,2, \ldots, n)
$$

The upper bound, $P_{u i}$, is the non-sway buckling strength of the column, while the lower bound, $P_{l i}$, can be prescribed by the user to consider the load of the column. $K_{c, i}$ is the column effective length factor. Note that this constraint assumes that the columns remain in ambient temperature. If the columns are heated significantly, then $E_{c, i}$ may need to be reduced and inelastic buckling behaviour may need to be considered, which is beyond the scope of this investigation.

\subsection{Temperature Constraint}

Equation (6) is applicable for temperatures up to $1000^{\circ} \mathrm{C}$. Assuming that the ambient temperature is $20^{\circ} \mathrm{C}$, the following temperature constraint is required for all beams:

$$
20^{\circ} \mathrm{C} \leq T_{b, j} \leq 1000^{\circ} \mathrm{C} \quad \forall j
$$

\subsection{Single Fire Constraint}

Further in addition to the above constraints, it may be desirable to limit the fire scenarios to represent a single spreading fire. It is usually either unrealistic or overly conservative to expect a case where multiple fires start simultaneously in a building, unless considering the possibility of https://doi.org/10.1016/j.jcsr.2018.04.003

(C) 2018. This manuscript version is made available under the CC-BY-NC-ND 4.0 license http://creativecommons.org/licenses/by-nc-nd/4.0/ 
a post-earthquake fire or rare scenarios such as the simultaneously occurring fires in WTC 7 caused by the attacks of September 11, 2001 [20]. It can be assumed in the case of a single fire that the fire can spread only via passage to adjacent compartments. The temperatures of the beams in compartments downstream of the fire origin will therefore be lower than the temperatures of beams in upstream compartments. As such, there cannot be multiple regions of local maximum temperatures in the model, and the following optional constraint is proposed:

$$
T_{b, j}-\operatorname{median}\left\{T_{b, r}, T_{b, j}, T_{b, s}\right\} \geq 0 ; \quad \forall 1 \leq r<j<s \leq n \quad \forall 2 \leq j \leq n-1
$$

where $T_{b, j}$ is the temperature of the beam in an internal compartment $j$, and $T_{b, r}$ and $T_{b, s}$ are the temperatures of beams to the left and right of compartment $j$. The inequality in Equation (12) must be satisfied for all combinations of $r$ and $s$ to the left and right of beam $j$, for all interior beams. This constraint effectively prevents any internal beam from having a lower temperature than both of its adjacent members.

\subsection{Objective Functions}

Obviously, there are infinite different combinations of $T_{b, j}$ that will satisfy the above constraints, which means that the frame can fail under many different scenarios. The goal of the proposed formulation is to identify only the significant scenarios resulting in failure of a structural steel frame by using objective functions. Two objective functions are proposed: one is based on average temperature throughout the frame, and the other is based on the locality of the fire. In the temperature-based approach, the maximum and minimum temperature loading scenarios are identified. Similar to the original formulation shown in Equations (4), these scenarios represent the best- and worst-case scenarios of loading causing instability of the frame. Knowledge of the best- and worst-case scenarios and identifying the weak points in a structure with regards to fire 
resistance can be useful in design, as the scenarios provide information on where and how a structural design can be improved. In the locality-based approach, the most localized and most distributed fires causing instability are determined. The locality-based approach is relevant to the concept of compartmentalization in fire safety engineering, where the goal of compartment design is to isolate fires to prevent spread. It cannot be said whether the most localized or distributed scenarios necessarily represent best- or worst-case scenarios.

\subsubsection{Temperature Function}

The first objective function determines the minimum and maximum average temperature of the beams, $T_{b, a v g}$, that will cause storey-based lateral instability, presented by the following objective function:

$$
\max _{\min } T_{b, a v g}=\frac{1}{n} \sum_{i=i}^{n} T_{b, j}
$$

subjected to the constraints in Equations (13b, $\mathrm{c}$ and d), and the optional single-fire constraint in Equation (13e):

$$
\begin{gathered}
\sum_{i=1}^{n} S_{c, i}=12 \sum_{i=1}^{n}\left(\frac{E_{c, i} I_{c, i}}{L_{c, i}^{3}} \beta_{c, i}\left(\phi_{c, i}, r_{l, c, i}, r_{u, c, i}\right)\right)=0 \\
P_{1 i} \leq P_{i} \leq P_{u i}=\frac{\pi^{2} E_{c, i} I_{c, i}}{\left(K_{c, i} L_{c, i}\right)^{2}} \quad(i=1,2, \ldots, n) \\
20^{\circ} \mathrm{C} \leq T_{b, j} \leq 1000^{\circ} \mathrm{C} \quad \forall j \\
T_{b, j}-\operatorname{median}\left\{T_{b, r}, T_{b, j}, T_{b, s}\right\} \geq 0 ; \quad \forall 1 \leq r<j<s \leq n \quad \forall 2 \leq j \leq n-1
\end{gathered}
$$

For this objective function, the worst-case scenario corresponds to the smallest temperature load for the applied column loads that will cause instability, and is obtained by minimizing $T_{b, a v g}$ in Equation (13a). The best-case scenario corresponds to the largest temperature load together with https://doi.org/10.1016/j.jcsr.2018.04.003

(C) 2018. This manuscript version is made available under the CC-BY-NC-ND 4.0 license http://creativecommons.org/licenses/by-nc-nd/4.0/ 
the applied column loads that will cause instability, and is obtained by maximizing $T_{b, a v g}$ in Equation (13a). The optimization problem can be solved using the Generalized Reduce Gradient (GRG) Nonlinear Programming method [21], among others.

\subsubsection{Locality Function}

It may alternatively be desirable to identify the most local fire causing instability, and as well as the most distributed fire causing instability. The corresponding objective function is given as follows:

$$
{ }_{\min }^{\max } \psi=\frac{T_{b, \max }}{T_{b, \text { avg }}}=\frac{T_{b, \max } n}{\sum_{i=i}^{n} T_{b, j}}
$$

where $\psi$ is the locality factor. Higher values of $\psi$ indicate abrupt variations of local maximum temperatures, while lower values of $\psi$ indicate less variation in temperatures throughout the frame. The objective function is subjected to the constraints in Equations (13b, c and d), and the optional constraint in Equation (13e):

$$
\begin{gathered}
\sum_{i=1}^{n} S_{c, i}=12 \sum_{i=1}^{n}\left(\frac{E_{c, i} I_{c, i}}{L_{c, i}^{3}} \beta_{c, i}\left(\phi_{c, i}, r_{l, c, i}, r_{u, c, i}\right)\right)=0 \\
P_{1 i} \leq P_{i} \leq P_{u i}=\frac{\pi^{2} E_{c, i} I_{c, i}}{\left(K_{c, i} L_{c, i}\right)^{2}} \quad(i=1,2, \ldots, n) \\
20^{\circ} \mathrm{C} \leq T_{b, j} \leq 1000^{\circ} \mathrm{C} \quad \forall j \\
T_{b, j}-\operatorname{median}\left\{T_{b, r}, T_{b, j}, T_{b, s}\right\} \geq 0 ; \quad \forall 1 \leq r<j<s \leq n \quad \forall 2 \leq j \leq n-1
\end{gathered}
$$

Maximizing $\psi$ identifies the "most localized fire", and can be used to identify the most critical compartments in which fires can start to cause the fastest collapse. Minimizing $\psi$ identifies the "most distributed fire", and it is noted that the minimum value of $\psi$ is unity, representing https://doi.org/10.1016/j.jcsr.2018.04.003 (C) 2018. This manuscript version is made available under the CC-BY-NC-ND 4.0 license http://creativecommons.org/licenses/by-nc-nd/4.0/ 
uniform temperature distribution throughout the frame. Similar to the average temperature function, the optimization problem of Equation (13a) can be solved using the Generalized Reduce Gradient (GRG) Nonlinear Programming method [21].

\subsection{Damage Contribution Factor}

It may be desirable to identify the critical columns governing failure of a frame under fire conditions. To do this, a damage contribution factor, $D_{c, i}$ is introduced, defined as the percentage ratio of the loss of lateral stiffness of column $i$ to the total loss of lateral stiffness of the frame at the point of failure:

$$
\begin{gathered}
D_{c, i}=\left(\Delta S_{c, i} / \sum_{i=1}^{n} \Delta S_{c, i}\right) * 100 \% \\
\Delta S_{c, i}=S_{T, c, i}-S_{o, c, i}
\end{gathered}
$$

where $S_{o, c, i}$ is the lateral stiffness of column $i$ if the frame is subjected to ambient temperature conditions, $S_{T, c, i}$ is the lateral stiffness of column $i$ when the frame is subjected to elevated temperature conditions, and $\Delta S_{c, i}$ is the change in lateral stiffness of column $i$ resulting from elevated temperatures. It can be shown that the frame relies more heavily on columns with higher values of $D_{c, i}$ to maintain stability. In order words, the frame will degrade more severely when a column with higher ambient stiffness is affected by elevated temperatures. As such, it is useful to report the values of $D_{c, i}$ so that the fire engineer can determine the most critical compartment in any scenario in order make an informed decision on which beams to upsize or protect to increase the fire performance of the frame.

\subsection{Analysis Procedure}

A computational procedure for using the proposed formulation is provided as follows:

https://doi.org/10.1016/j.jcsr.2018.04.003

(C) 2018. This manuscript version is made available under the CC-BY-NC-ND 4.0 license http://creativecommons.org/licenses/by-nc-nd/4.0/ 
1. Input basic member properties $\left(L_{c, i}, L_{b, i}, E_{c, i}, E_{b, i} I_{c, i} I_{b, i}\right)$, axial loads $\left(P_{i}\right)$, and any known or assumed support conditions $\left(r_{u, c, i}, r_{l, c, i}, r_{b, j, N}, r_{b, j, F}\right)$. Specify $v=1$ and $P_{l i}$ as necessary.

2. Select an objective function from either Equation (13) or (14) to minimize or maximize. Choose and run a non-linear optimization subroutine that minimizes or maximizes the objective function by varying the beam temperatures while satisfying all of the constraints. In general, the subroutine should iterate Steps 3 through 6 in some way.

3. Assign a trial set of beam temperatures $\left(T_{b, j}\right)$, and set column temperatures $\left(T_{c, i}\right)$ equal to $20^{\circ} \mathrm{C}$. The trial set should be determined through use of constrained non-linear optimization algorithms.

4. Calculate the reduced stiffness properties of the members and resulting end fixity factors of connecting members $\left(E_{c, i}, E_{b, j}, R_{u, c, i}, R_{l, c, l}, r_{u, c, i}, r_{l, c, i}\right)$.

5. Compute $K_{c, i}$ and $P_{u i}$ for each column and ensure that $P_{i}$ is within the range in Equation (10). Otherwise, return to Step 3.

6. Evaluate the lateral stiffness of the frame according to Equation (7). If the lateral stiffness is not zero, iterate Steps 3 through 6 until the constraint is satisfied.

7. Once a set of temperatures is found that satisfies all of the stability constraints, evaluate the optimality of the solution according to the value of the objective function, and store information about the optimal solution as necessary. Return to Step 3 to find other feasible solutions.

8. When the convergence criteria for the optimization subroutine is achieved, output the optimal solution according to the objective function, and calculate $D_{c, i}$ if desired. The output represents the most significant scenario found by the subroutine according to the objective function. 


\section{NUMERICAL EXAMPLES}

Two example frames were analysed using the proposed formulation. The minimum and maximum solutions for each of the temperature and locality objective functions were identified for each frame.

\subsection{Example 1}

The first example is a symmetrical four-bay frame with all column bases pinned $\left(r_{l}=0\right)$, presented in $[7,11]$ and shown in the figure below.

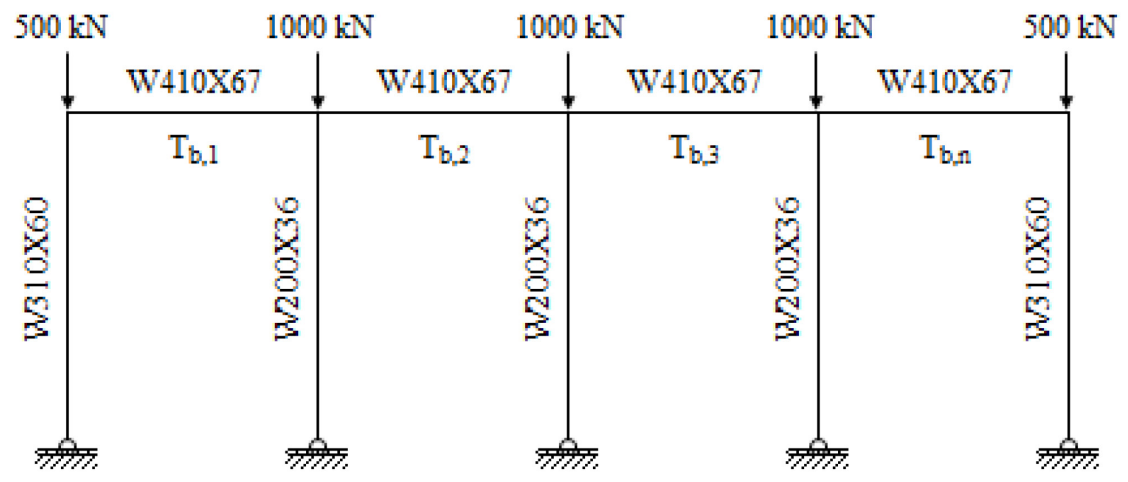

Figure 3 - Frame for Example 1

The heights of the columns are $4.877 \mathrm{~m}(16 \mathrm{ft}$.), and the lengths of the beams are $7.315 \mathrm{~m}(24 \mathrm{ft}$.$) .$ The temperatures of the beams in each bay are $T_{b, 1}, T_{b, 2}, T_{b, 3}$ and $T_{b, 4}$. The axial loads on the external columns and internal columns are given as $500 \mathrm{kN}$ and $1000 \mathrm{kN}$, respectively. The end fixity factors for both ends of all the beams are taken as unity at ambient temperatures which signifies that beam ends are rigidly connected to the columns. The lateral stiffness of each column in the frame at ambient temperature for Example 1 is given in the following table.

Table 1 - Column lateral stiffness values for ambient temperature condition, Example 1

\begin{tabular}{|c|c|c|c|c|c|c|}
\hline \multirow{2}{*}{$\frac{\text { Scenario }}{\text { Ambient condition }}$} & \multicolumn{5}{|c|}{ Column lateral stiffness at ambient temperature, $S_{0, c, i}$} & $\Sigma S_{o, c, i}$ \\
\hline & $365 \mathrm{kN} / \mathrm{m}$ & $-80 \mathrm{kN} / \mathrm{m}$ & $-80 \mathrm{kN} / \mathrm{m}$ & $-80 \mathrm{kN} / \mathrm{m}$ & $365 \mathrm{kN} / \mathrm{m}$ & $490 \mathrm{kN} / \mathrm{m}$ \\
\hline
\end{tabular}


The total lateral stiffness of the frame at ambient temperature is $490 \mathrm{kN} / \mathrm{m}$. The negative stiffness associated with the interior columns results from the effects of axial loading, which indicates that the interior columns rely on the lateral support of exterior columns in order to carry loads. Therefore, the integrity of the external columns is critical to the stability of the frame. Solving the optimization problem with the single-fire constraint enabled and maximizing the temperature-based objective function gives the results shown in the following table, where values of $S_{T, c, i}, D_{c, i}, T_{b, j}$ and $T_{b, a v g}$ are reported as the conditions occurring when the lateral stiffness of the frame reaches zero.

Table 2 - Maximum temperature instability scenario with single-fire constraint enabled for Example 1

\begin{tabular}{c|c|c|c|c|c}
\hline \multicolumn{7}{c}{ Maximize $\boldsymbol{T}_{b, a v g}$ with single fire constraint } \\
\hline Average temperature, $T_{b, a v g}$ & \multicolumn{5}{c}{$\mathbf{8 4 5}^{\circ} \mathbf{C}$} \\
\hline Beam temperatures, $T_{b, j}$ & $\mathbf{7 0 0}^{\circ} \mathbf{C}$ & $\mathbf{1 0 0 0}^{\circ} \mathbf{C}$ & \multicolumn{2}{c}{$\mathbf{9 7 4}^{\circ} \mathbf{C}$} & $7^{\circ} \mathbf{C}$ \\
\hline Column lateral stiffness $S_{T, c, I}$ & $187 \mathrm{kN} / \mathrm{m}$ & $-100 \mathrm{kN} / \mathrm{m}$ & $-180 \mathrm{kN} / \mathrm{m}$ & $-100 \mathrm{kN} / \mathrm{m}$ & $192 \mathrm{kN} / \mathrm{m}$ \\
\hline Column damage contribution, $D_{c, i}$ & $35 \%$ & $4 \%$ & $20 \%$ & $4 \%$ & $36 \%$ \\
\hline
\end{tabular}

It can be seen that the maximum temperature scenario has very high temperatures in every compartment. It may represent that of a fire starting in one of the internal compartments and spreading towards the outside or multiple fires in the buildings. Note that even though the internal beams experience high temperature and have lost virtually all of their load carrying capacities, the internal columns only contribute about $28 \%$ to the total loss of strength causing instability. Conversely, even though the external compartments have the lowest temperatures, the external columns contribute about $71 \%$ of the total strength loss. Minimizing the average temperature gives the results in the following table: 
Table 3 - Minimum temperature instability scenario with single-fire constraint enabled for Example 1

Minimize $T_{b, a v g}$ with single fire constraint

\begin{tabular}{c|c|c|c|c|c|c}
\hline Average temperature, $T_{b, a v g}$ & \multicolumn{5}{|c}{$\mathbf{4 3 3}^{\circ} \mathbf{C}$} \\
\hline Beam temperatures, $T_{b, j}$ & $\mathbf{2 0}^{\circ} \mathbf{C}$ & \multicolumn{2}{|c}{$\mathbf{2 0}^{\circ} \mathbf{C}$} & \multicolumn{2}{|c}{$\mathbf{6 9 2}^{\circ} \mathbf{C}$} & $\mathbf{1 0 0 0}^{\circ} \mathbf{C}$ \\
\hline Column lateral stiffness $S_{T, c, I}$ & $365 \mathrm{kN} / \mathrm{m}$ & $-80 \mathrm{kN} / \mathrm{m}$ & $-82 \mathrm{kN} / \mathrm{m}$ & $-100 \mathrm{kN} / \mathrm{m}$ & $-103 \mathrm{kN} / \mathrm{m}$ \\
\hline Column damage contribution, $D_{c, i}$ & $0 \%$ & $0 \%$ & $0 \%$ & $4 \%$ & $96 \%$ \\
\hline
\end{tabular}

The minimum temperature scenario shows that if a fire starts in an end compartment, it can cause instability of the frame without needing to spread past the first internal bay. In such a case, $96 \%$ of the total strength loss is attributed to the external column. As such, the both the maximum and minimum temperature scenarios show that the integrity of the end columns are critical and control the failure under fire conditions for this frame. Clearly, the minimum temperature scenario is also more dangerous than the maximum temperature scenario because a lower average temperature is required to cause instability.

The example was solved again using the temperature-based objective function, but without the single-fire constraint applied. The maximum temperature scenario is shown in the table below:

Table 4 - Maximum temperature instability scenario with single-fire constraint disabled for Example 1

Maximize $T_{b, a v g}$ without single fire constraint

\begin{tabular}{c|c|c|c|c|c|c}
\hline Average temperature, $T_{b, a v g}$ & \multicolumn{5}{|c}{$\mathbf{8 4 5}^{\circ} \mathbf{C}$} \\
\hline Beam temperatures, $T_{b, j}$ & $\mathbf{7 0 0}^{\circ} \mathbf{C}$ & $\mathbf{1 0 0 0}^{\circ} \mathbf{C}$ & \multicolumn{2}{|c}{$\mathbf{9 7 4}^{\circ} \mathbf{C}$} & $\mathbf{7 0 6}^{\circ} \mathbf{C}$ \\
\hline Column lateral stiffness $S_{T, c, I}$ & $187 \mathrm{kN} / \mathrm{m}$ & $-100 \mathrm{kN} / \mathrm{m}$ & $-180 \mathrm{kN} / \mathrm{m}$ & $-100 \mathrm{kN} / \mathrm{m}$ & $192 \mathrm{kN} / \mathrm{m}$ \\
\hline Column damage contribution, $D_{c, i}$ & $35 \%$ & $4 \%$ & $20 \%$ & $4 \%$ & $36 \%$ \\
\hline
\end{tabular}

https://doi.org/10.1016/j.jcsr.2018.04.003

(C) 2018. This manuscript version is made available under the CC-BY-NC-ND 4.0 license

http://creativecommons.org/licenses/by-nc-nd/4.0/ 
The maximum temperature scenario is the same as that with the single-fire constraint applied. The corresponding results of the minimum temperature scenario withour single-fire constraint applied is shown in the table below:

Table 5 - Minimum temperature instability scenario with single-fire constraint disabled for Example 1

\begin{tabular}{|c|c|c|c|c|c|}
\hline \multicolumn{6}{|c|}{ Minimize $T_{b, a v g}$ without single fire constraint } \\
\hline \multirow{2}{*}{$\frac{\text { Average temperature, } T_{b, a v g}}{\text { Beam temperatures, } T_{b, j}}$} & \multicolumn{5}{|c|}{$338^{\circ} \mathrm{C}$} \\
\hline & $1000^{\circ} \mathrm{C}$ & 20 & & ${ }^{\circ} \mathrm{C}$ & $311^{\circ} \mathrm{C}$ \\
\hline Column lateral stiffness $S_{T, c, I}$ & $-103 \mathrm{kN} / \mathrm{m}$ & $-85 \mathrm{kN} / \mathrm{m}$ & $-80 \mathrm{kN} / \mathrm{m}$ & $-80 \mathrm{kN} / \mathrm{m}$ & $348 \mathrm{kN} / \mathrm{m}$ \\
\hline Column damage contribution, $D_{c, i}$ & $96 \%$ & $1 \%$ & $0 \%$ & $0 \%$ & $4 \%$ \\
\hline
\end{tabular}

Prior to disabling the single fire constraint, the minimum case was an average temperature of $433^{\circ} \mathrm{C}$. With the single-fire constraint disabled, the minimum case is reduced to $338^{\circ} \mathrm{C}$, representing the rare case of a fully developed fire on one end of the frame accompanied by a second developing fire on the other end. This demonstrates that more critical but unlikely scenarios can be found by disabling the single-fire constraint.

The results of the locality-based objective function were also retrieved for Example 1. Maximizing the locality-based objective function to identify the most localized fire scenario resulting in instability gives the following results:

Table 6 - Most localized fire instability scenario with single-fire constraint enabled for Example 1

Maximize $\psi$ with single fire constraint

\begin{tabular}{c|c|c|c|c|c|c}
\hline Locality factor, $\psi$ & \multicolumn{5}{|c}{$\mathbf{2 . 3 1}$} \\
\hline Beam temperatures, $T_{b, j}$ & $\mathbf{2 0}^{\circ} \mathbf{C}$ & \multicolumn{2}{|c}{$\mathbf{2 0}^{\circ} \mathbf{C}$} & \multicolumn{2}{|c}{$\mathbf{6 9 2}^{\circ} \mathbf{C}$} & $\mathbf{1 0 0 0}^{\circ} \mathbf{C}$ \\
\hline Column lateral stiffness $S_{T, c, I}$ & $365 \mathrm{kN} / \mathrm{m}$ & $-80 \mathrm{kN} / \mathrm{m}$ & $-82 \mathrm{kN} / \mathrm{m}$ & $-100 \mathrm{kN} / \mathrm{m}$ & $-103 \mathrm{kN} / \mathrm{m}$ \\
\hline Column damage contribution, $D_{c, i}$ & $0 \%$ & $0 \%$ & $0 \%$ & $4 \%$ & $96 \%$ \\
\hline
\end{tabular}


The most localized fire occurs at an end bay, and is identical to the minimum temperature scenario for the same frame shown in Table 3. This shows that the worst case fires found using the temperature-based objective function can also be the most localized fires, representing severe fires that develop in single, critical compartments. The locality-based objective function was also minimized and the results are shown in the table below:

Table 7 - Most distributed fire instability scenario with single-fire constraint enabled for Example 1

Minimize $\psi$ with single fire constraint

\begin{tabular}{c|c|c|c|c|c|c}
\hline Locality factor, $\psi$ & \multicolumn{5}{|c}{1.00} \\
\hline Beam temperatures, $T_{b, j}$ & $\mathbf{7 6 3}^{\circ} \mathbf{C}$ & $\mathbf{7 6 3}^{\circ} \mathbf{C}$ & $\mathbf{7 6 3}^{\circ} \mathbf{C}$ & $\mathbf{7 6 3}^{\circ} \mathbf{C}$ \\
\hline Column lateral stiffness $S_{T, c, I}$ & $141 \mathrm{kN} / \mathrm{m}$ & $-94 \mathrm{kN} / \mathrm{m}$ & $-94 \mathrm{kN} / \mathrm{m}$ & $-94 \mathrm{kN} / \mathrm{m}$ & $141 \mathrm{kN} / \mathrm{m}$ \\
\hline Column damage contribution, $D_{c, i}$ & $46 \%$ & $3 \%$ & $3 \%$ & $3 \%$ & $46 \%$ \\
\hline
\end{tabular}

The most distributed fire is the case of uniform temperature of $763^{\circ} \mathrm{C}$ throughout the frame. Once again, the $D_{c, i}$ values of the columns indicate that the strength of the frame relies heavily on the integrity of the end columns.

\subsection{Example 2}

The frame and applied loads in the second example are identical to that of Example 1, except that the lower end of the central column is changed to be fixed to the ground $\left(r_{l}=1\right)$. It intends to investigate the effects of strengthening an internal column. The lateral stiffness of each column in the frame subjected to applied loads at ambient temperature for Example 2 is given in the following table.

Table 8 - Column lateral stiffness values for ambient temperature condition, Example 2

\begin{tabular}{c|c|c|c|c|c|c}
\hline Scenario & \multicolumn{5}{|c|}{ Column lateral stiffness at ambient temperature, $S_{0, c, i}$} & $\Sigma S_{o, c, i}$ \\
\hline Ambient condition & $365 \mathrm{kN} / \mathrm{m}$ & $-80 \mathrm{kN} / \mathrm{m}$ & $427 \mathrm{kN} / \mathrm{m}$ & $-80 \mathrm{kN} / \mathrm{m}$ & $365 \mathrm{kN} / \mathrm{m}$ & $\mathbf{9 9 7} \mathbf{~ k N} / \mathbf{m}$ \\
\hline
\end{tabular}

https://doi.org/10.1016/j.jcsr.2018.04.003

(C) 2018. This manuscript version is made available under the CC-BY-NC-ND 4.0 license

http://creativecommons.org/licenses/by-nc-nd/4.0/ 
The total lateral stiffness of the frame at ambient temperature is $997 \mathrm{kN} / \mathrm{m}$. The only difference between this example and Example 1 is that the lateral stiffness of the central column at ambient temperature was increased from $-80 \mathrm{kN} / \mathrm{m}$ to $427 \mathrm{kN} / \mathrm{m}$ due to the strengthening the column base. Solving the optimization problem with the single-fire constraint enabled and maximizing the temperature-based objective function yields the results shown in the following table:

Table 9 - Maximum temperature instability scenario with single-fire constraint enabled for Example 2

Maximize $T_{b, a v g}$ with single fire constraint

\begin{tabular}{c|c|c|c|c|c|c}
\hline Average temperature, $T_{b, a v g}$ & \multicolumn{6}{|c}{$\mathbf{9 0 7}{ }^{\circ} \mathbf{C}$} \\
\hline Beam temperatures, $T_{b, j}$ & $\mathbf{8 6 7}^{\circ} \mathbf{C}$ & $\mathbf{1 0 0 0}^{\circ} \mathbf{C}$ & \multicolumn{2}{|c}{$\mathbf{8 8 1}^{\circ} \mathbf{C}$} & $\mathbf{8 8 1}^{\circ} \mathbf{C}$ \\
\hline Column lateral stiffness $S_{T, c, I}$ & $45 \mathrm{kN} / \mathrm{m}$ & $-128 \mathrm{kN} / \mathrm{m}$ & $164 \mathrm{kN} / \mathrm{m}$ & $-112 \mathrm{kN} / \mathrm{m}$ & $31 \mathrm{kN} / \mathrm{m}$ \\
\hline Column damage contribution, $D_{c, i}$ & $32 \%$ & $5 \%$ & $26 \%$ & $3 \%$ & $34 \%$ \\
\hline
\end{tabular}

The maximum temperature scenario is similar to that in Example 1 except the temperatures are higher due to the increased robustness of the frame. Minimizing the temperature-based objective function gives the following results:

Table 10 - Minimum temperature instability scenario with single-fire constraint enabled for Example 2

Minimize $T_{b, a v g}$ with single fire constraint

\begin{tabular}{|c|c|c|c|c|c|}
\hline Average temperature, $T_{b, a v g}$ & \multicolumn{5}{|c|}{$742^{\circ} \mathrm{C}$} \\
\hline Beam temperatures, $T_{b, j}$ & $950^{\circ} \mathrm{C}$ & 1000 & & $0^{\circ} \mathrm{C}$ & $20^{\circ} \mathrm{C}$ \\
\hline Column lateral stiffness $S_{T, c, I}$ & $-43 \mathrm{kN} / \mathrm{m}$ & $-162 \mathrm{kN} / \mathrm{m}$ & $-75 \mathrm{kN} / \mathrm{m}$ & $-85 \mathrm{kN} / \mathrm{m}$ & $365 \mathrm{kN} / \mathrm{m}$ \\
\hline Column damage contribution, $D_{c, i}$ & $41 \%$ & $8 \%$ & $50 \%$ & $0 \%$ & $0 \%$ \\
\hline
\end{tabular}

The minimum temperature scenario represents a fire that is much more spread out than that in Example 1, but is still contained within three compartments. Also, the average temperature increased from $433^{\circ} \mathrm{C}$ to $742^{\circ} \mathrm{C}$, showing a significant increase in overall capacity. Since the https://doi.org/10.1016/j.jcsr.2018.04.003

(C) 2018. This manuscript version is made available under the CC-BY-NC-ND 4.0 license http://creativecommons.org/licenses/by-nc-nd/4.0/ 
middle column is fixed to the ground, it now shares a greater portion of the damage contribution $(50 \%)$ in the critical scenario than in Example 1. Maximizing the locality-based objective function with the single-fire constraint enabled to find the most localized fire causing instability gives the following results:

Table 11 - Most localized fire instability scenario with single-fire constraint enabled for Example 2

Maximize $\psi$ with single fire constraint

\begin{tabular}{c|c|c|c|c|c|c}
\hline Locality factor, $\psi$ & \multicolumn{5}{|c}{1.35} \\
\hline Beam temperatures, $T_{b, j}$ & $\mathbf{9 5 0}{ }^{\circ} \mathbf{C}$ & \multicolumn{1000}{c}{$\mathbf{C}$} & \multicolumn{2}{|c}{$\mathbf{1 0 0 0}^{\circ} \mathbf{C}$} & $\mathbf{2 0}^{\circ} \mathbf{C}$ \\
\hline Column lateral stiffness $S_{T, c, I}$ & $-43 \mathrm{kN} / \mathrm{m}$ & $-162 \mathrm{kN} / \mathrm{m}$ & $-75 \mathrm{kN} / \mathrm{m}$ & $-85 \mathrm{kN} / \mathrm{m}$ & $365 \mathrm{kN} / \mathrm{m}$ \\
\hline Column damage contribution, $D_{c, i}$ & $41 \%$ & $8 \%$ & $50 \%$ & $0 \%$ & $0 \%$ \\
\hline
\end{tabular}

Once again, the most localized fire scenario corresponds to the minimum temperature scenario.

The most distributed fire scenario was obtained by minimizing the locality-based objective function, and the results are shown below:

Table 12 - Most distributed fire instability scenario with single-fire constraint enabled for Example 2

Minimize $\psi$ with single fire constraint

\begin{tabular}{|c|c|c|c|c|c|}
\hline Locality factor, $\psi$ & \multicolumn{5}{|c|}{1.00} \\
\hline Beam temperatures, $T_{b, j}$ & $904^{\circ} \mathrm{C}$ & $904^{c}$ & & $4^{\circ} \mathrm{C}$ & $904^{\circ} \mathrm{C}$ \\
\hline Column lateral stiffness $S_{T, c, I}$ & $7 \mathrm{kN} / \mathrm{m}$ & $-118 \mathrm{kN} / \mathrm{m}$ & $224 \mathrm{kN} / \mathrm{m}$ & $-118 \mathrm{kN} / \mathrm{m}$ & $7 \mathrm{kN} / \mathrm{m}$ \\
\hline Column damage contribution, $D_{c, i}$ & $36 \%$ & $4 \%$ & $20 \%$ & $4 \%$ & $36 \%$ \\
\hline
\end{tabular}

The most distributed scenario is a uniform temperature of $904^{\circ} \mathrm{C}$, which could roughly simulate the conditions of a post-flashover fire occurring throughout the entire level. Note that by fixing the middle column to the ground, the uniform temperature required to cause instability is increased by $141^{\circ} \mathrm{C}\left(\right.$ from $\left.763^{\circ} \mathrm{C}\right)$. 


\section{CONCLUSION}

Presented in this paper is a methodology of identifying the critical fire scenarios that result in instability of single-storey unbraced steel frames. These scenarios are the maximum and minimum average beam temperatures, and the most localized and most distributed fire scenarios. Unlike the traditional approach of assuming proportional loading, the proposed formulation is able to identify the minimum and maximum fire loading scenarios causing instability failure. Two frames were analyzed as examples, and it was found that the lowest average temperature scenarios causing instability of the frames represented those of localized fires starting in critical compartments, which are located at "strong" columns with the largest contributions toward maintaining structural integrity at ambient temperature. In contrast, the highest temperature scenarios causing instability of the frame represented fires starting in non-critical compartments and "weak" columns that did not significantly contribute to the stability of the frame at ambient temperature. The formulation was able to identify the critical columns in the frame by using a damage contribution factor. The formulation is useful for structural design as the results quantify the fire-structural performance with metrics that are easy to understand, and the results change meaningfully if the configuration of the frame is strengthened or weakened.

\section{ACKNOWLEDGEMENTS}

The authors wish to thank the National Science and Engineering Research Council (NSERC) of Canada for the financial support of this work. 


\section{REFERENCES}

1. British Research Establishment. (1996). Fire, static, dynamic tests at the large building test facility. Proceedings of the $2^{\text {nd }}$ Cardington Conference.

2. Couto, C., Real, P.V., Lopes, N., Rodrigues, J.P. (2013). Buckling analysis of braced and unbraced steel frames exposed to fire. Engineering Structures, vol. 49, pp. 541-559.

3. Rackauskaite, E., Kotsovinos, P., Jeffers, A., Rein, G. (2017). Structural analysis of multistorey steel frames exposed to travelling fires and traditional design fires. Engineering Structures, vol. 150, pp. 271-287.

4. Xu, L., Zhuang, Y. (2014). Storey stability of unbraced steel frames subjected to nonuniform elevated temperature distribution. Engineering Structures, vol. 62-63, pp. 164-173.

5. Toh, W.S., Fung, T.C., Tan, K.H. (2001). Fire resistance of steel frames using classical and numerical methods. Journal of Structural Engineering, vol. 127, no. 7, pp. 829-838.

6. $\mathrm{Xu}, \mathrm{L}$. (2001). The buckling loads of unbraced PR frames under non-proportional loading. Journal of Constructional Steel Research, vol. 58, pp. 443-465.

7. Zhuang, Y. (2013). Storey-based stability analysis of unbraced steel frames at ambient and elevated temperatures (Doctoral thesis, University of Waterloo, Waterloo, ON).

8. Yura, J. (1971). The effective length of columns in unbraced frames. Engineering Journal, vol. 8 , no. 2, pp 37-42.

9. LeMessurier, W. (1977). A practical method of second order analysis Part 2 - Rigid Frames. Engineering Journal, vol. 14, no. 2, pp. 49-67.

10. Lui, E. (1992). A novel approach for K factor determination. AISC, Engineering Journal, vol. 4, pp. 150-159. 
11. Xu, L. (2003). A NLP approach for evaluating storey-buckling strengths of steel frames under variable loading. Structural and Multidisciplinary Optimization, vol. 25, no. 2, pp. $141-150$.

12. Buchanan, A.H., Abu, A.K. (2017). Structural Design for Fire Safety. John Wiley \& Sons, Ltd.

13. ASTM International. (2016). Standard Test Methods for Fire Tests of Building Construction and Materials (ASTM E119-16a). West Conshohocken, PA.

14. International Organization for Standardization. (1999). Fire Resistance Tests-Elements of Building Construction (ISO 834). Switzerland.

15. European Committee for Standardization. (2002). Actions on structures - Part 1-2: General actions - actions on structures exposed to fire (Eurocode 1). Brussels, Belgium.

16. Prete, I.D., Cefarelli, G., Nigro. E. (2016). Application of criteria for selecting fire scenarios for structures within fire safety engineering approach. Journal of Building Engineering, vol. 8, pp. 208-217.

17. Lie, T. T. (1992). Structural Fire Protection. American Society of Civil Engineers, New York. Wang, Y.C., Kodur, V.K.R. (2000). Research toward the use of unprotected steel structures. Journal of Structural Engineering, vol. 126, no. 12, pp. 1442-1450.

18. Kodur, V.K.R. (2003). Role of fire resistance issues in the collapse of the Twin Towers. CIB $2^{\text {nd }}$ Global Leaders Summit on Tall Buildings, Kuala Lumpur, Malaysia.

19. Kodur, V.K.R. (2004). Role of fire resistance issues in the first ever collapse of a steelframed building - WTC 7. CIB World Building Congress 2004, Toronto, ON.

20. Lasdon, L.S., Fox, R.L, Ratner, M.W. (1973). Nonlinear optimization using the generalized reduced gradient method. Case Western Reserve University, Cleveland, OH. 